\title{
POLONIUM IN CIGARETTE SMOKE AND RADIATION EXPOSURE OF LUNGS
}

\author{
FERnANDo P. CARVALho*) AND JoÃo M. Oliveira \\ Instituto Tecnológico e Nuclear \\ Departamento de Protecção Radiológica e Segurança Nuclear \\ E.N. 10, 2686-953 Sacavém, Portugal
}

\begin{abstract}
Polonium $\left({ }^{210} \mathrm{Po}\right)$, the most volatile of naturally-occurring radionuclides in plants, was analysed in three common brands of cigarettes produced in Portugal. The analyses were carried out on the unburned tobacco contained in cigarettes, on the ashes and butts of smoked cigarettes and on the mainstream smoke. ${ }^{210} \mathrm{Po}$ in tobacco displays concentrations ranging from 3 to $37 \mathrm{mBq} \mathrm{g}{ }^{-1}$, depending upon the cigarette brand. The ${ }^{210} \mathrm{Po}$ activity remaining in the solid residue of a smoked cigarette varied from 0.3 to $4.9 \mathrm{mBq}$ per cigarette, and the ${ }^{210} \mathrm{Po}$ in the inhaled smoke varied from 2.6 to $28.9 \mathrm{mBq}$. In all brands of cigarettes tested, a large fraction of the ${ }^{210} \mathrm{Po}$ content is not inhaled by the smoker and it is released into the atmosphere. Part of it may be inhaled by passive smokers. Depending upon the commercial brand and upon the presence or absence of a filter in the cigarette, 5 to $37 \%$ of the ${ }^{210} \mathrm{Po}$ in the cigarette can be inhaled by the smoker. Taking into account the average ${ }^{210} \mathrm{Po}$ in surface air, the smoker of one pack of twenty cigarettes per day may inhale 50 times more ${ }^{210} \mathrm{Po}$ than a non smoker. Cigarette smoke contributes with $1.5 \%$ to the daily rate of ${ }^{210} \mathrm{Po}$ absorption into the blood, $0.39 \mathrm{~Bq} \mathrm{~d}^{-1}$, and, after systemic circulation it gives rise to a whole body radiation dose in the same proportion. However, in the smoker the deposition of ${ }^{210} \mathrm{Po}$ in the lungs is much more elevated than normal and may originate an enhanced radiation exposure. Estimated dose to the lungs is presented and radiobiological effects of cigarette smoke are discussed.
\end{abstract}

\section{Introduction}

Radioactivity was suggested as a possible causative agent for the lung cancer and, at least in the case of the occupational exposure of uranium miners to radon and radon daughters, this has been supported with epidemiological data [1-3]. Radioactivity in the cigarette smoke was measured by several authors and it was suggested that ionizing radiation from cigarette smoke could originate a meaningful exposure of lung tissues $[4,5]$. Amongst the naturally-occurring radio nuclides measured in the leaf of tobacco plant, which include uranium, thorium, radium $\left({ }^{226} \mathrm{Ra}\right)$ and polonium $\left({ }^{210} \mathrm{Po}\right)$, the last one is present in the highest activity concentrations [6].

${ }^{210} \mathrm{Po}\left(\mathrm{T}_{1 / 2}=138.4 \mathrm{~d}\right)$ is a uranium series radionuclide with a high energy alpha particle emission $\left(\mathrm{E}_{\alpha}=5.305 \mathrm{MeV}\right)$, close to the energy of ${ }^{239} \mathrm{Pu}\left(\mathrm{E}_{\alpha}=5.155 \mathrm{MeV}\right)$, and both are considered highly radiotoxic for cells and able to cause cancer at very low mass concentrations [7].

\footnotetext{
${ }^{*}$ E-mail: carvalho@itn.pt
} 
Although ${ }^{210} \mathrm{Po}$ naturally occurs in the environment and in the human body, cigarette smoke is a supplementary source of ${ }^{210}$ Po that may enhance radiation dose to the lungs in a significant manner.

This paper reports results for radionuclide analyses in tobacco and cigarette smoke consumed by the Portuguese population.

\section{Materials and Methods}

Cigarettes of the three most popular commercial brands produced and consumed in Portugal were analyzed for radionuclide concentrations in the tobacco leaf material already treated and incorporated in cigarettes. As different cigarette brands generally have different preparation and blending procedures, differences in radionuclide concentrations may occur. For instance, the drying stage of the tobacco plant leaf may last from few months to more than one year which will allow for significant growth of ${ }^{210}$ Po from ${ }^{210} \mathrm{~Pb}$ radioactive decay with time.

Cigarettes of the same brand were smoked with an aspirating-puffing device, based on a flow adjusted peristaltic pump. The mainstream smoke was collected on a double glass micro fiber filters (GF/F, Whatman) plus a 5 liter bottle with acidified water for bubbling the filtered air. The glass fiber filters, water filter and three washes of the system with acidified distilled water, were combined in one sample for analysis representing the smoke inhaled by the smoker.

The ashes and the cigarette butts were analyzed in order to determine the non-volatile ${ }^{210} \mathrm{Po}$ activity and to compute the ${ }^{210} \mathrm{Po}$ activity released into the atmosphere and potentially available for inhalation by passive smokers. Each cigarette brand was analyzed in five replicate experiments.

Analyses of ${ }^{210} \mathrm{Po}$ were performed after addition of a known activity of ${ }^{209} \mathrm{Po}\left(\mathrm{E}_{\alpha}=\right.$ $4.882 \mathrm{MeV}$ ) and thorough homogenization of the sample. ${ }^{209} \mathrm{Po}$ is used as an internal isotopic tracer allowing for internal quality control of the radiochemical recovery yield. After equilibration, the samples were evaporated and dissolved in mineral acids. Organic matter was oxidized with $\mathrm{H}_{2} \mathrm{O}_{2}$, and, finally, the evaporation residue dissolved in $50 \mathrm{~mL}$ of $0.5 \mathrm{M} \mathrm{HCl}$. Polonium isotopes were spontaneously plated on a silver disc, in the presence of $200 \mathrm{mg}$ of ascorbic acid as a reducing agent. Measurements were performed by alpha spectrometry with ion implanted silicon surface barrier detectors, $450 \mathrm{~mm}^{2}$ active surface, calibrated with electroplated $\mathrm{Pu}-\mathrm{Am}-\mathrm{Cm}$ standard sources from ORIS/CEA, France (Fig. 1).

\section{Results and Discussion}

Analytical results are shown in Tables 1 and 2. The three brands of commercial cigarettes roughly have similar amounts of tobacco per cigarette, but the specific activity of ${ }^{210} \mathrm{Po}$ in the tobacco is very different in the various brands, varying from 2.8 to $37 \mathrm{mBq}$ $\mathrm{g}^{-1}$ (dry weight) (Table 1).

Analyses of ${ }^{210} \mathrm{Po}$ in the main stream smoke or inhaled fraction, indicate nearly similar activity in the smoke for the same brand of tobacco in cigarettes with and without fil- 


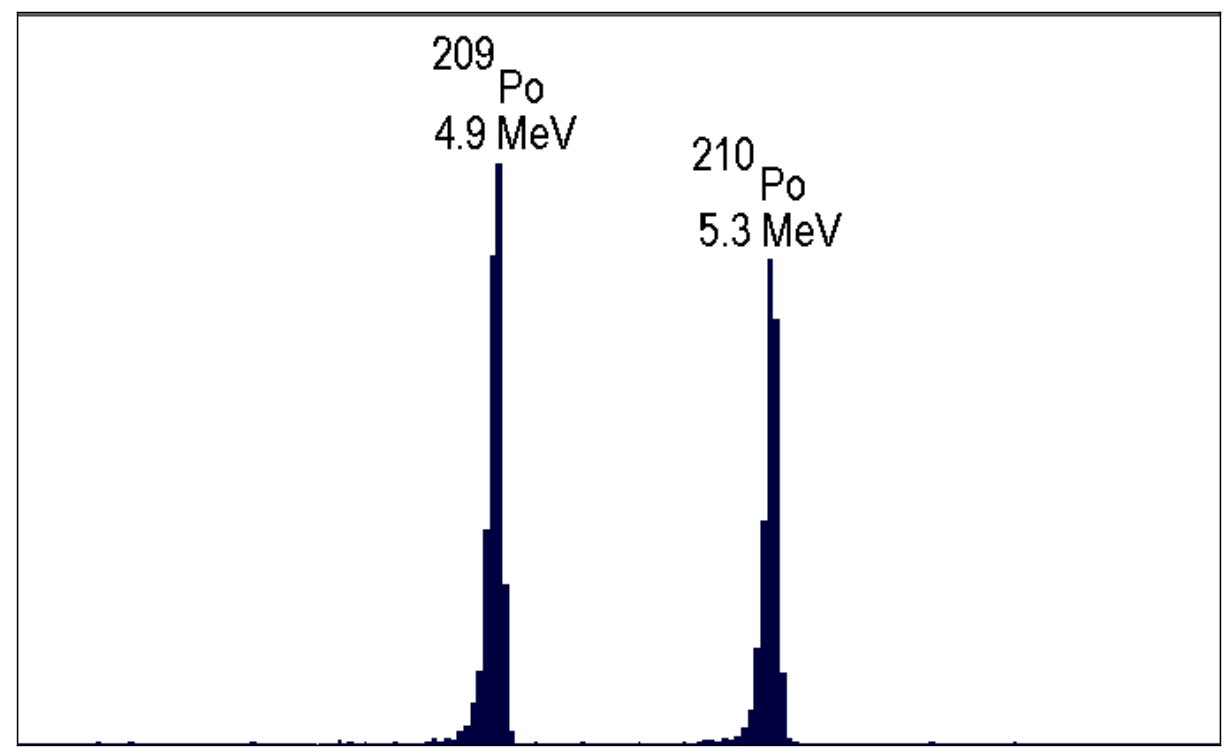

Fig. 1. Alpha spectrogram of polonium in a cigarette smoke sample.

Table 1. Cigarettes: amount of tobacco and ${ }^{210} \mathrm{Po}$ activity

\begin{tabular}{|l|c|c|c|}
\hline Cigarette brand & $\begin{array}{c}\text { Tobacco/cigarette } \\
(\mathrm{g})\end{array}$ & $\begin{array}{c}{ }^{210} \mathrm{Po} \text { concentration } \\
\left(\mathrm{mBq} \mathrm{g}^{-1}\right.\end{array}$ & $\begin{array}{r}{ }^{210} \mathrm{Po} / \text { cigarette } \\
(\mathrm{mBq})\end{array}$ \\
\hline $\begin{array}{l}\text { "Português Suave } \\
\text { Filtro" (with filter) } \\
\text { "Português Suave" } \\
\text { (without filter) }\end{array}$ & 0.748 & 37 & 27.7 \\
$\begin{array}{l}\text { "SG Light" } \\
\text { (with filter) }\end{array}$ & 0.793 & 15 & 11.9 \\
\hline
\end{tabular}

Table 2. Concentration of ${ }^{210} \mathrm{Po}$ in cigarette smoke and residues

\begin{tabular}{|c|c|c|c|c|c|c|c|c|}
\hline \multirow{3}{*}{ Brand } & \multicolumn{7}{|c|}{${ }^{210}$ Po activity per cigarette } & \multirow{3}{*}{$\begin{array}{c}{ }^{210} \mathrm{Po} \\
\text { inhalation } \\
\text { (mBq per } \\
20 \text { cigarettes) }\end{array}$} \\
\hline & \multicolumn{2}{|c|}{$\begin{array}{l}\text { Main stream } \\
\text { smoke }\end{array}$} & \multicolumn{2}{|c|}{$\begin{array}{c}\text { Residue } \\
\text { (ash + butt) }\end{array}$} & \multicolumn{2}{|c|}{$\begin{array}{l}\text { Side stream } \\
\text { smoke }\end{array}$} & \multirow{2}{*}{$\begin{array}{l}\text { Total } \\
\mathrm{mBq}\end{array}$} & \\
\hline & $\mathrm{mBq}$ & $\%$ tot. & $\mathrm{mBq}$ & $\%$ tot. & $\mathrm{mBq}$ & $\%$ tot. & & \\
\hline $\begin{array}{l}\text { "PS } \\
\text { filtro" }\end{array}$ & 1.52 & 5.2 & 2.1 & 7.2 & 24.4 & 84 & 28.9 & 30 \\
\hline "PS" & 1.37 & 11.2 & 4.9 & 40.0 & 5.9 & 49 & 12.2 & 27 \\
\hline $\begin{array}{l}\text { "SG } \\
\text { Light", }\end{array}$ & 0.97 & 37.3 & 0.3 & 11.5 & 1.3 & 51 & 2.6 & 19 \\
\hline
\end{tabular}


ter, 1.52 and $1.32 \mathrm{mBq}$ respectively, but much lower activity in the smoke of "light" cigarettes, $0.97 \mathrm{mBq}$ (Table 2). Activity measured in the ash and butts of all brands ranged from $7 \%$ to $40 \%$ of the total ${ }^{210} \mathrm{Po}$ initially contained in cigarettes. Volatilization of ${ }^{210} \mathrm{Po}$ during cigarette burning can be noticed in the results, especially in the low percent activity remaining with ash and butts (Table 2 ). This is due to the low polonium volatilization point $\left(180^{\circ} \mathrm{C}\right)$ in comparison with the combustion temperature of cigarettes $(600-$ $800^{\circ} \mathrm{C}$ ). The volatilization of polonium facilitates the release of the radionuclide from tobacco and its association and transport with the smoke particles inhaled. Other radio nuclides, such as lead $\left({ }^{210} \mathrm{~Pb}\right)$ and bismuth $\left({ }^{210} \mathrm{Bi}\right)$ are likely carried also with the smoke particles in the air inhaled by the smoker but in relatively smaller amounts due to higher volatilization temperatures [8].

In the cigarettes with filter the solid residues retain 7.2 and $11.5 \%$ of ${ }^{210} \mathrm{Po}$ while in the cigarettes without filter the remaining activity attains $40 \%$, although this is due also to a large contribution of the unburned tobacco in the butt (Table 2). Based on the activity of cigarette residues, it could be noted that ${ }^{210} \mathrm{Po}$ retention in cigarettes with filter is not higher than in cigarettes without filter, and, therefore, the filter was not an effective barrier to retain ${ }^{210} \mathrm{Po}$ volatilized from the tobacco.

In all tested brands, $50 \%$ of more of the cigarette ${ }^{210} \mathrm{Po}$ content was present neither in the mainstream smoke nor in the residues but, instead, was released into the air with the side stream smoke. This smoke may be inhaled by passive smokers or lost in the atmosphere.

Radiation doses from polonium $\left({ }^{210} \mathrm{Po}\right)$ and its grand-parent radioactive lead $\left({ }^{210} \mathrm{~Pb}\right)$ to man are known to occur following inhalation and ingestion of these radio nuclides. $[8,9]$ A previous work on the concentration of both radio nuclides in the diet of the Portuguese population allowed the computation of daily ingestion rates of $1.3 \mathrm{~Bq} \mathrm{~d}^{-1}$ and $0.56 \mathrm{~Bq} \mathrm{~d}^{-1}$ for ${ }^{210} \mathrm{Po}$ and ${ }^{210} \mathrm{~Pb}$, respectively.[10] The higher concentrations of ${ }^{210} \mathrm{Po}$ compared to those of ${ }^{210} \mathrm{~Pb}$ in the diet, are due to high consumption rates of marine food, about $60 \mathrm{~kg} \mathrm{a}{ }^{-1}$ per capita, with ${ }^{210} \mathrm{Po} /{ }^{210} \mathrm{~Pb}$ ratios above unity, i.e. above radioactive equilibrium.

Inhalation of these radio nuclides with airborne particles gives a contribution to the absorption of ${ }^{210} \mathrm{Po}$ and ${ }^{210} \mathrm{~Pb}$ in the blood adding to the gut absorption of radio nuclides ingested with food. Average concentrations of ${ }^{210} \mathrm{Po}$ and ${ }^{210} \mathrm{~Pb}$ in the surface air at Sacavém, near Lisbon, are $31 \times 10^{-6} \mathrm{~Bq} \mathrm{~m}^{-3}$ and $181 \times 10^{-6} \mathrm{~Bq} \mathrm{~m}^{-3}$ respectively [11]. Assuming a daily inhalation of $20 \mathrm{~m}^{3}$ of air (Standard Man, as defined by the ICRP), the inhalation rate of these radio nuclides is $6.2 \times 10^{-4} \mathrm{~Bq} \mathrm{~d}^{-1}$ and $3.6 \times 10^{-3} \mathrm{~Bq} \mathrm{~d}^{-1}$, respectively.

Inhalation of cigarette smoke is a supplementary exposure to ${ }^{210} \mathrm{Po}$ radionuclide. Variable percentages, between 5 to $37 \%$, of the cigarette ${ }^{210} \mathrm{Po}$ content are inhaled with the mainstream smoke by the smoker. In the worst case, a blended type cigarette with filter, the consumption of one pack of 20 cigarettes per day gives rise to a ${ }^{210} \mathrm{Po}$ inhalation rate of $0.03 \mathrm{~Bq} \mathrm{~d}^{-1}$.

Systemic exposure to ${ }^{210} \mathrm{Po}$ from cigarette smoke requires previous absorption of the radionuclide into the bloodstream and distribution to the internal organs and tissues, by the same processes as for naturally occurring airborne ${ }^{210} \mathrm{Po}$. 
Natural background radiation exposure due to ${ }^{210} \mathrm{Po}$, and also ${ }^{210} \mathrm{~Pb}$, can be assessed for individuals of the Portuguese population as follows.

Following inhalation of air, the absorption of ${ }^{210} \mathrm{Po}$ and ${ }^{210} \mathrm{~Pb}$ into the blood stream may be computed as

$A_{2}=I_{2} \times D_{5} \times f_{2}+I_{2} \times D_{5} \times f_{1} \times f_{3}$,

where

$\mathrm{A}_{2}$ is the daily activity absorbed into the blood stream from inhalation $\left(\mathrm{Bq} \mathrm{d}^{-1}\right)$,

$\mathrm{I}_{2}$ is the radionuclide inhalation rate $\left(\mathrm{Bq} \mathrm{d}^{-1}\right)$

$\mathrm{D}_{5}$ is the fraction of inhaled particles that are deposited in the lungs (0.45),

$\mathrm{f}_{1} \quad$ is the fraction absorbed by the digestive tract $(0.3)$,

$\mathrm{f}_{2}$ is the fraction of particulate activity deposited in the lungs that is absorbed through the alveolus $(0.20)$,

$\mathrm{f}_{3}$ is the fraction of particles deposited in lungs that later is swollen and transferred to the gut (0.80) [12-14].

To the population living in the Lisbon area, the radionuclide absorption rate from inhaled air into the blood stream, $\mathrm{A}_{2}$, is $1.2 \times 10^{-4} \mathrm{~Bq} \mathrm{~d}^{-1}$ for ${ }^{210} \mathrm{Po}$, and $7.1 \times 10^{-4} \mathrm{~Bq} \mathrm{~d}^{-1}$ for ${ }^{210} \mathrm{~Pb}$.

Smokers of one pack of cigarettes per day absorb $6 \times 10^{-3} \mathrm{~Bq} \mathrm{~d}^{-1}$ of ${ }^{210} \mathrm{Po}$ from the cigarette smoke into the bloodstream, i.e., one order of magnitude above ${ }^{210} \mathrm{Po}$ absorption by non smokers.

For comparison purposes, we can also take into consideration the average ingestion rate of these radio nuclides, i.e., 1.3 and $0.56 \mathrm{~Bq} \mathrm{~d}^{-1}$ for ${ }^{210} \mathrm{Po}$ and ${ }^{210} \mathrm{~Pb}$, respectively.

Absorption of radio nuclides from food into the blood stream can be computed by

$A_{1}=I_{g} \times f_{1}$,

where

$\mathrm{A}_{1}$ is the daily absorption of radionuclide into the blood,

$\mathrm{I}_{\mathrm{g}}$ is the daily intake of the radionuclide $\left(\mathrm{Bq} \mathrm{d}^{-1}\right)$,

$\mathrm{f}_{1} \quad$ is the gut transfer factor.

Making $\mathrm{f}_{1}=0.3$ for adults [13], the absorption rate of ${ }^{210} \mathrm{Po}$ from food is $0.39 \mathrm{~Bq} \mathrm{~d}^{-1}$ and absorption rate of ${ }^{210} \mathrm{~Pb}$ is $0.17 \mathrm{~Bq} \mathrm{~d}^{-1}$.

Taking into account the overall intake of ${ }^{210} \mathrm{Po}$ by both ingestion and inhalation, in the Portuguese population the average absorption of ${ }^{210} \mathrm{Po}$ from food is much higher than absorption from air. Inhalation of air contributes to about $0.03 \%$ only to ${ }^{210} \mathrm{Po}$ absorbed daily into the blood stream and contributes to about $3 \%$ of ${ }^{210} \mathrm{~Pb}$ absorbed daily.

For both radio nuclides, the ingestion pathway largely dominates over the inhalation pathway for the internal exposure to these radio nuclides. This means that for the contamination of internal organs, including the radio nuclides from cigarette smoke, the inhalation pathway gives a minor contribution to the radionuclide concentrations in internal tissues.

The whole body radiation dose due to systemic exposure to ${ }^{210} \mathrm{Po}$ from cigarette smoke can be computed in terms of committed effective dose using the dose conversion factor for members of the public $3.3 \times 10^{-6}$ [7]. The result is a committed effective dose of $36 \mu \mathrm{Sv} \mathrm{a}^{-1}$ in a smoking person, and $0.7 \mu \mathrm{Sv} \mathrm{a}^{-1}$ in a non smoker, a tiny fraction in the whole-body radiation exposure of $2.6 \mathrm{mSv} \mathrm{a}^{-1}$ due to all radiation sources [10]. 
Nevertheless, a smoking person may still receive a cumulative dose of $1.08 \mathrm{mSv}$ over 30 years smoking.

Lung exposure. However, exposure of lung tissues to the alpha radiation emitted by ${ }^{210}$ Po might be significantly enhanced with inhalation of cigarette smoke.

A non smoker inhaling naturally-occurring airborne ${ }^{210} \mathrm{Po}$ in Lisbon inhales $6.2 \times 10^{-4}$ $\mathrm{Bq} \mathrm{d}^{-1}$, i.e., $0.226 \mathrm{~Bq} \mathrm{a}^{-1}$. A smoker of a pack a day, inhales $30 \mathrm{mBq} \mathrm{d}^{-1}$, i.e., $10.95 \mathrm{~Bq}$ $\mathrm{a}^{-1}$ from cigarette smoke plus the airborne ${ }^{210} \mathrm{Po}$, i.e., a total of about $11 \mathrm{~Bq} \mathrm{a}^{-1}$ or about 50 times more than a non smoking person.

Inhaled ${ }^{210}$ Po likely enters the lung attached to aerosol particles and deposits on the walls of alveolar parenchyma. This radionuclide deposit receives continuous input through inhalation and it is subject to radioactive decay as well as lung clearance by biophysical mechanisms, maintaining a steady state activity that can be written as

$\mathrm{I}_{2} \times \mathrm{D}_{5}-\mathrm{k}_{\mathrm{eff}} \times \mathrm{L}_{\mathrm{D}}=0$,

where

$\mathrm{I}_{2}$ is the radionuclide inhalation rate $\left(\mathrm{Bq} \mathrm{d}^{-1}\right)$,

$\mathrm{D}_{5}$ is the fraction of inhaled particles that are deposited in the alveolus (0.45),

$\mathrm{k}_{\mathrm{eff}}$ is the effective lung clearance rate for ${ }^{210} \mathrm{Po}\left(\mathrm{k}_{\mathrm{eff}}=\ln 2 / \mathrm{T}_{1 / 2} 40 \mathrm{~d}=0.0173 \mathrm{~d}^{-1}\right)$ and

$\mathrm{L}_{\mathrm{D}}$ is the lung deposit of ${ }^{210} \mathrm{Po}$ [9].

For an addicted smoker of a pack a day the computed ${ }^{210}$ Po lung deposit is $780 \mathrm{mBq}$. Assuming uniform distribution of this activity in the lung tissue (1 kg wet weight), concentration of ${ }^{210} \mathrm{Po}$ is $\mathrm{C}=780 \mathrm{mBq} \mathrm{kg}{ }^{-1}$ and the absorbed dose $\mathrm{D}_{\mathrm{a}}$ is estimated as $\mathrm{D}_{\mathrm{a}}=$ $0.027 \times \mathrm{C}=21 \mu \mathrm{Gy} \mathrm{a}^{-1}$. Using a radiation quality factor of 20 for ${ }^{210} \mathrm{Po}$, the dose equivalent to the lung is computed at $0.42 \mathrm{mSv} \mathrm{a}^{-1}$. This value is probably an underestimate of the dose because ${ }^{210}$ Po may concentrate in aggregates on the tracheobronchial epithelium and radiation dose may be locally higher.

Cancer risk factor. It is generally accepted that the risk factor of contracting a fatal cancer following whole body exposure to ionizing radiation is $5.0 \times 10^{-2} \mathrm{~Sv}^{-1}$ person $^{-1}$ ( 1 case in 20 per $\mathrm{Sv}$ ) and for the exposure of lung tissue the risk factor is twice $0.85 \times$ $10^{-2} \mathrm{~Sv}^{-1}[7]$.

The risk of fatal cancer from whole body exposure to ${ }^{210} \mathrm{Po}$ from cigarette smoke followed by lung absorption and systemic distribution, in a population of 3 million smokers and for 30 years of cumulative exposure, leads to an excess of 162 fatalities to be added to cancers from all other causes.

However, the deposition of ${ }^{210} \mathrm{Po}$ in smokers' lungs originates a large exposure of this organ. Taking the risk factor of fatal cancer due to radiation exposure of lungs as twice the value $0.85 \times 10^{-2} \mathrm{~Sv}^{-1}$ person ${ }^{-1}$, and assuming a population of 3 million smokers (almost one third of the Portuguese population) exposed individually to this radiation rate over 30 years, the number of excess casualties is estimated at 634. Taking fatal cancer endpoint as a measure of harm, this is the likely societal cost of ${ }^{210} \mathrm{Po}$ in cigarette smoke.

\section{Conclusions}

Concentrations of ${ }^{210} \mathrm{Po}$ in cigarettes produced in Portugal are in the range of values reported in the literature. Cigarette burning releases into the inhaled smoke a large frac- 
tion of the ${ }^{210} \mathrm{Po}$ in tobacco. Inhalation of ${ }^{210} \mathrm{Po}$ with cigarette smoke gives a small contribution to the systemic exposure to ${ }^{210} \mathrm{Po}$ in comparison to the much larger activity of this radionuclide, and of its grand parent ${ }^{210} \mathrm{~Pb}$, absorbed from food.

However, the exposure of lungs to the inhaled ${ }^{210} \mathrm{Po}$ is significantly enhanced in the smoking person and the exposure of this critical organ increases the risk of occurrence of a fatal cancer. The number of fatal cancers in the Portuguese population caused by ${ }^{210} \mathrm{Po}$ in the cigarette smoke is estimated at 634 excess casualties to be added to fatal cancers from all other causes.

\section{References}

[1] Kusiak, R.A., Ritchie, A: C: , Muller, J., and Springer, J.: Br. J. Ind.Med. 50(1) (1993) 9208.

[2] ICRP (1993). Protection against Radon at Home and at Work. ICRP Publication 65. Pergamon; Oxford, UK.

[3] UNSCEAR (2000). Sources and Effects of Ionizing Radiation. United Nations Scientific Committee on the Effects of Atomic Radiation. UNSCEAR 2000 Report to the General Assembly, Vol. I. United Nations, New York.

[4] Mussalo-Rauhamaa, H. and Jaakola, T.: Health Physics 49(2) (1985) 296-301.

[5] Takizawa, Y., Zhang, L. and Zhao, L.: Journal of Radioanalytical and Nuclear Chemistry 182 (1994) 19-125.

[6] Santos, M.S., Azeredo, A.M.G.F., Melo, D.R., and Julião L.M.Q.C.: Journal Radioanalytical and Nuclear Chemistry 182 (1994) 57-62.

[7] ICRP (1996). Age-dependent Doses to Members of the Public from Intake of Radionuclides, Part 5, Compilation of Ingestion and Inhalation Dose Coefficients. ICRP Publication $\mathrm{N}^{\mathrm{o}} 72$, Ann. ICRP 26, Elsevier Science, Oxford, UK.

[8] Holtzman, R.: In: The Biogeochemistry of Lead in the Environment (Part B). J.O. Nriagu Ed., pp 37-96. Elsevier/North Holland Pub., 1978.

[9] Parfenov, Y.D.: Atom.Energy Rev., 12 (1974) 75.

[10] Carvalho, F.P.: Health Physics 69(4) (1995) 469.

[11] Carvalho, F.P.: Atmospheric Environment 29 (15) (1995) 1809.

[12] Magno, P.J., Groulx, P.R., and Apidianakis, J.C.: Health Physics 18 (1970) 383.

[13] Kendall, G.M., Harrison, J.D., and Fell, T.D.: Radiation Protection Dosimetry 25 (1988) 5965 .

[14] Human Respiratory Tract Model for Radiological Protection, ICRP Publication No. 66, Ann. ICRP 24, 1-3, Elsevier Science, Oxford, UK, 1994. 